\title{
Erratum
}

\section{Changes in alkaline phosphatase activity and phosphate uptake in $P$-limited phytoplankton, induced by light intensity and spectral quality}

\author{
D. Wynne ${ }^{1,2} \&$ G.-Y. Rhee ${ }^{1 *}$ \\ ${ }^{1}$ Wadsworth Center for Laboratories and Research, New York State Department of Health, Albany, \\ NY 12201, U.S.A. (*author for correspondence). ${ }^{2}$ Permanent address: Israel Oceanographic \& \\ Limnological Research, The Yigal Allon Kinneret Limnological Laboratory, P.O. Box 345, \\ Tiberias 14102, Israel
}

Hydrobiologia 160: 173-178, 1988

On page 176 of the above article, reference was made to Table 1 . Unfortunately this table was inadvertently omitted from the final printed version, and we present it here below, with apologies for any inconvenience to the authors and readers.

The Publishers

Table 1. Half-saturation constant $\left(K_{s}\right)$ and maximum uptake rate $\left(V_{\max }\right)$ under four light spectra.*

\begin{tabular}{|c|c|c|c|c|c|}
\hline \multirow[t]{2}{*}{ Species } & \multirow[t]{2}{*}{ Parameter } & \multicolumn{4}{|c|}{ Colour $\left(58 \mu \mathrm{E} \mathrm{m}^{-2} \mathrm{~s}^{-1}\right)$} \\
\hline & & White & Red & Green & Blue \\
\hline \multirow[t]{2}{*}{ Thalassiosira pseudonana } & $K_{s}$ & $1.68(0.35)^{* *}$ & $1.74(0.36)$ & $0.79(0.17)$ & $0.51(0.15)$ \\
\hline & $V_{\max }$ & $1.14(0.12)$ & $0.47(0.05)$ & $1.32(0.11)$ & $0.75(0.08)$ \\
\hline \multirow[t]{2}{*}{ Phaeodactylum tricornutum } & $K_{s}$ & $0.53(0.15)$ & $0.30(0.04)$ & - & $0.40(0.09)$ \\
\hline & $V_{\max }$ & $0.32(0.03)$ & $0.27(0.02)$ & - & $0.27(0.02)$ \\
\hline \multirow[t]{2}{*}{ Dunaliella tertiolecta } & $K_{s}$ & $1.72(0.34)$ & $2.26(0.97)$ & - & $1.94(0.80)$ \\
\hline & $V_{\max }$ & $0.92(0.08)$ & $5.15(1.40)$ & - & $1.50(0.35)$ \\
\hline \multirow[t]{2}{*}{ Prymnesium parvum } & $K_{s}$ & $1.60(0.56)$ & $2.48(0.86)$ & $0.87(0.13)$ & $0.41(0.07)$ \\
\hline & $V_{\max }$ & $0.24(0.05)$ & $0.11(0.03)$ & $0.09(0.006)$ & $0.14(0.006)$ \\
\hline
\end{tabular}

* $K_{s}$ is measured in $\mu \mathrm{M} . V_{\max }$ is measured in $10^{-10} \mu \mathrm{mol} \mathrm{P}$ cell ${ }^{-1} \mathrm{~min}^{-1}$.

** Values in parentheses are standard errors. 